\title{
Congenital sternal ectopia cordis in a Limousin calf - a case report
}

\author{
Hieronim Frąckowiak ${ }^{1}$, Jędrzej Maria Jaśkowski², Maria Nabzdyk ${ }^{1}$, Beata Kociucka ${ }^{3}$, \\ Izabela Szczerbal ${ }^{3}$, Marek Switonski ${ }^{3}$, Dorota Bukowska ${ }^{2}$, Paweł Antosik ${ }^{2}$ \\ Poznań University of Life Sciences, Institute of Zoology, 'Department of Animal Anatomy, \\ ${ }^{2}$ Institute of Veterinary Sciences, ${ }^{3}$ Department of Genetics and Animal Breeding, Poznań, Poland
}

Received March 22, 2013

Accepted December 4, 2013

\begin{abstract}
Recognition and detailed description of malformations and aberrations in domestic animals may be very useful in cognition of the problem and in creating breeding programs. The aim of this study was to describe a rare case of sternal (pectoral) ectopia cordis in a calf. A female calf of the Limousin breed born in Poland in 2011 was subjected to euthanasia because the heart was situated outside the chest. The carcass of the calf was subjected to anatomical examination in which alterations in cardiovascular system and in the structure of the sternum were observed. Cytogenetic studies were performed to find out if the karyotype of the calf was normal. Elongation of the ascending aorta was observed and the pattern of aortic branching was aberrant similarly to that found in dogs, not cattle. The systemic circulation was found to be linked to pulmonary circulation due to persisting large calibre arterial duct. Each of the ventricles had its own cardiac apex and walls of the ventricles manifested a similar width. The atria were slightly altered. A single, short and dilated blood vessel (pulmonary vein) evacuated its content to the left atrium. Pericardium formed no pericardial sac. Radiogram of the sternum demonstrated a ring-resembling shape and 12 (6 pairs) cartilaginous bars of the sternum (sternebrae). A normal female karytotype $(60, \mathrm{XX})$ indicated that this malformation was not caused by an abnormal number of chromosomes (aneuploidy).
\end{abstract}

Cattle, arterial pattern, sternum, chromosomes

Ectopia cordis represents a developmental error involving the transposition of the heart outside the chest. Depending on the site to which displacement occurs, it is classified as cervical ectopia cordis (upper or lower ectopia), pectoral or sternal ectopia, and abdominal ectopia (Herzog and Wiedeking 1970; Shiran et al. 2010). Moreover, cases of thoracoabdominal and cervico-pectoral ectopia (Hiraga et al. 1990) were also reported.

Manifestation of this developmental error has been detected in almost all livestock species (Hamali and Ashrafihelan 2010). However, vast majority of the reports of ectopia cordis concerned cattle (Wyrost and Radek 1982), and it was less frequent in horses (Hamali and Ashrafihelan 2010). Individuals affected by ectopia cordis in cattle died soon after birth or survived even several years, most frequently till maturity (Murakami et al. 1996).

In this study we present a rare case of ectopia cordis of the pectoral (or sternal) type in a Limousin heifer.

\section{Materials and Methods}

Heart displacement (ectopia cordis) outside the chest was described in a newborn female calf of the Limousin breed born in Poland in 2011 on a commercial farm (birth weight $34 \mathrm{~kg}$ ). The calf was the third offspring (all three female) of the cow and the delivery, similar to the preceding ones, took place by forces of nature. The sire of the calf was one of two bulls, since a harem mating system was followed on the farm. The calf proved to be viable and healthy, with a preserved sucking reflex. The heart, situated out of the chest, manifested a rhythmic pulsation of 132 contractions per minute. The owner of the farm decided on euthanasia which was performed by a veterinary surgeon by intravenous injection of pentobarbital $16 \mathrm{mg} / \mathrm{kg}$ (Morbital Biowet, Poland).

The anatomical alteration of the heart was examined post mortem. Arteries were filled with stained LBS 3060 latex ( $650 \mathrm{ml}$ injected into the left ventricle) and then the heart was fixed in $10 \%$ formalin and subjected to manual

Address for correspondence:

Nabzdyk Maria

Poznań University of Life Sciences

Department of Animal Anatomy, Institute of Zoology

Wojska Polskiego 71c, 60-625 Poznań, Poland 
preparation. In order to facilitate inspection of cardiac cavities, the latex was removed from ventricles and atria. Using an electronic calliper, lengths and diameters of certain blood vessels were measured. The sternum was separated and its radiograms were prepared using the $\mathrm{x}$-ray apparatus CR3X-PRO.

Moreover, cytogenetic studies were performed to find out if the karyotype of the calf was normal. Chromosome preparations were obtained from fibroblast culture, derived from skin samples collected post mortem. The cells were cultured for 2 weeks and treated with colcemid solution followed by hypotonic treatment $(0.075 \mathrm{M} \mathrm{KCl})$ and fixation (methanol:acetic acid, 3:1). Air dried microscopic slides were stained with Giemsa and analyzed under a Nikon E600 Eclipse microscope, equipped with a cooled digital CCD camera and computer-aided software LUCIA. International nomenclature of bovine chromosomes (Cribiu et al. 2001) was applied to analyze a karyotype of the studied case.

\section{Results}

The calf's heart was situated outside the chest, in the sternal region to the left from the sagittal plane. The heart was not situated in a pericardial sac (Plate IV, Fig. 1) which was absent, and a portion of fibrous pericardium with a parietal layer of serous pericardium was positioned also outside the chest, over the sternum and caudally in relation to the heart. The remaining part of pericardium was a closed opening in the sternum, adhering to the diaphragm. The heart and pericardium underwent displacement from the chest to the sternal region through the ring-like opening of $220 \times 100 \mathrm{~mm}$ size, surrounded by a modified sternum of an appropriately adjusted shape. Each of the cardiac ventricles had its own apex while the atria were slightly altered and they differed from atria in anatomically normal valves by a richer sculpture of auricles. Thickness of walls in both cardiac ventricles was similar and amounted to around $10 \mathrm{~mm}$. The right ventricle was enlarged.

The ascending portion of the aorta was elongated (length of around $100 \mathrm{~mm}$, diameter of around $11 \mathrm{~mm}$ ) and the arch of the aorta was not clearly marked. The aorta branched first directly into the left subclavian artery and next into the brachocephalic trunk which was divided into three branches: left common carotid artery, right common carotid artery and right subclavian artery (Plate IV, Fig. 2). After it connected with the ductus arteriosus, the aorta broadened significantly, reaching a diameter of around $20 \mathrm{~mm}$. The descending aorta gradually narrowed reaching in the abdominal part at the level of origin of visceral celiac artery the diameter of around $13 \mathrm{~mm}$. The thoracic and abdominal portions of the aorta yielded branches typical for the cattle, also terminal branches of the aorta provided arteries typical for the species.

The brachiocephalic trunk of $53 \mathrm{~mm}$ in length and $17 \mathrm{~mm}$ in diameter was narrower compared to the trunk stemming from the right ventricle pulmonary trunk, the diameter of which reached $70 \mathrm{~mm}$. The arterial duct manifested no traits of obliteration. Five pulmonary veins (of a diameter ranging from 6 to $19 \mathrm{~mm}$ ) joined at first a single short and dilated blood vessel which evacuated its blood into the left atrium. The cranial vena cava and the caudal vena cava joined the right atrium. Presence of the right and left azygos vein was noted. Atrio-ventricular ostia as well as the origin of the aorta from the left ventricle and of the pulmonary trunk from the right ventricle were supplied with normally developed valves. Foramen ovale in the interatrial septum was patent.

Translocation of the heart resulted in a modified structure of the sternum which acquired a ring-like shape (Plate V, Fig. 3). Analysis of the radiogram indicated that 12 sternebrae were arranged in 6 pairs on each side of the ring-like sternum. The ectopia cordis resulted in skoliosis or right-side arcuate bending of the thoracic vertebral column and in asymmetry of subaxial muscles (psoas major muscles). Moreover, the ventral portion of the spleen was bent under a straight angle and directed medially.

Cytogenetic studies demonstrated that out of 100 examined metaphase plates, 96 manifested the normal diploid number of chromosomes $(2 n=60, X X)$, while 4 metaphases were tetraploid $(4 n)$. This indicates that aneuploidy was not responsible for the observed malformation. 


\section{Discussion}

The heart of the calf with sternal ectopia cordis described in our study was not enclosed in the pericardial sac, and two cardiac apices were observed. This finding was similar to a case report in a calf described by Nakay ama (1985) and to ectopia cordis cervicalis in a calf (where the heart had 2 apices, but was in the pericardial sac) described by Hiraga and Abe (1986), Hiraga et al. (1993), and Shiran et al. (2010). The calf in our study showed also similar thickness of walls in both ventricles and an atrial structure distinct from the anatomical norm.

The altered pattern of the aortal arch branches of the calf in our study was similar to the pattern of the branches in dogs and other carnivores. A similarly modified pattern of aortal arch branches (dog type) in cases of cervical ectopia cordis in cattle was described by Hiraga and Abe (1986). In the case of sternal ectopia cordis, the branching pattern of the discussed arteries was defined by Nakayama (1985) as a hybrid pig-cattle pattern. Hiraga et al. (1993) suggested that changes in the aorta arch branching pattern in cattle takes place in an embryo of a 17-22 $\mathrm{mm}$ crown-rump length and they involve preservation of the beginning of the left subclavian artery origin directly from the aortal arch or on persistence of the primitive vascular pattern.

In our study, we detected presence of a functioning arterial duct (of a significant diameter) which provided a shunt between systemic circulation and pulmonary circulation. Wyrost (1981) detected absence of separation between the systemic and pulmonary circulation in cattle with ectopia cordis. Cranial vena cava in certain cases of ectopia cordis was represented by a two bilateral blood vessel (Hiraga and A be 1986; Hiraga et al. 1993). In our study, and in a similar case described by Nakayama (1985), cranial vena cava, in line with the anatomic norm represented a single blood vessel.

The transplacement of the heart (sternal ectopia cordis) induces anatomic lesions in the structure of the sternum. A detailed analysis of the sternal structure in calves affected by sternal ectopia cordis and various forms of ectopia cordis were presented by Hughes (1936) and Hiraga et al. (1993), respectively. In ectopia cordis the pectoral sternum assumed the shape of a keyhole (Hiraga et al. 1993). The number of sternebrae in normal cattle is 7 , whereas in calves affected by ectopia cordis cervicalis their number ranges from 13 to 26 , in cervico-pectoral ectopia cordis from 10 to 19 , and in pectoral ectopia cordis it was 11 (Hiraga et al. 1993). In our study, we demonstrated 12 sternebrae which formed 6 pairs, distributed on two sides of the ring-like sternum.

In cattle, development of the sternum starts on the $50^{\text {th }}$ day of pregnancy with the appearance of bilateral cartilaginous bars. On the $53^{\text {rd }}$ day of pregnancy, the bars are fully developed and on the $64^{\text {th }}$ day they manifest complete fusion (Lindsay 1969). Earlier, disturbances in fusion of the bilateral cartilaginous bars of the sternum were thought to be the cause of ectopia cordis. However, confronted with the new facts yielded by studies on the vascular system, this view may be abandoned for the advantage of a different opinion. The course of fusion of bilateral sternal bars is retarded if they are not blocked by premature juxtapositioning of the heart at the thoracic inlet (Hiraga et al. 1993), or premature positioning of the heart at the entry to the chest.

Analysis of the karyotype in a mother with cervical cardiac ectopia and her male calf demonstrated in both animals the typical diploid chromosome number 60, XX and 60, XY, respectively (Wyrost and Grabiński 1976). The identical result of 60, XX has been obtained in our study since $4 \%$ proportion of polyploid metaphases should be regarded as a non-significant artifact associated with in vitro cell culture. Thus, it can be concluded that this congenital malformation is not caused by aneuploidy, while structural chromosome aberration cannot be excluded. However, it should be pointed out that some malformed foetuses or stillborn calves carry autosome aneuploidies (Shoultz et al. 1996). Thus, cytogenetic examination of such calves is recommended. 
According to several authors, the cause of ectopia cordis manifestation remains unknown although suggestions have been published that it reflects an embryonic insult. On the other hand, it could be an influence of individual recessive genes or polygenic sets that have lesion-specific effects on the cardiac development (Radostits et al. 2007; Hamali and Ashrafihelan 2010).

Incidence of ectopia cordis is rearely observed in cattle populations and thus its unfavorable impact on the health status is small, especially compared to decreased reproductive performance related to multiple pregnancies (Sawa et al. 2012), the course of calving, or early death caused by diarrhoea (Slavik et al. 2009). In view of the unique character and low incidence of ectopia cordis, and the absence of clear aetiology of the malformation, further complex analyses of its cases are needed.

\section{References}

Hamali H, Ashrafihelan J 2010: A report on bovine fetal ectopia cordis cervicalis associated with two caervical sacs. Iran J Vet Res 11: 287-290

Herzog A, Wiedeking JF 1970: Ectopia cordis congenital beim Rind. Giessener Beitr Erbpathol Zuchthyg 1/2: $1-24$

Hiraga T, Abe M 1986: Eight calves of cervical ectopia cordis and their sternums. Jap J Vet Sci 48: 1199-1206

Hiraga T, Abe M, Iwasa K, Takechana K, Tanigaki A 1993: Cervico-pectoral ectopia cordis in two Holstein calves. Vet Pathol 30: 529-534

Hughes HV 1936: The sternum in ectopia cordis. Vet J 92: 225-226

Cribiu EP, Di Berardino D, Di Meo GP, Eggen A, Gallagher DS, Gustavsson I, Hayes H, Iannuzzi L, Popescu CP, Rubes J, Schmutz S, Stranzinger G, Vaiman A, Womack J 2001: International system for chromosome nomenclature of domestic bovids (ISCNDB 2000). Cytogenet Cell Genet 92: 283-299

Lindsay FE 1969: Observations on the loci of ossification in the prenatal and postnatal bovinae skeleton. II. The sternum. Br Vet J 125: 422-473

Murakami T, Hagio M, Moritomo Y Hamana K, Nakai M 1996: Anatomical observation on five cases of ectopia cordis in calves. Adv Anim Cardiol 29: 85-90

Nakayama Y 1985: A case of bovinae sternal ectopia cordis. MA Thesis, Rakuno Gakuen University, Ebetsu, Japan

Radostits OM, Gay CC, Hinchcliff KW, Constable PD 2007: Veterinary Medicine. $10^{\text {th }}$ Edn, Spain, WB Saunders Co. pp. 432-434

Sawa A, Bogucki M, Krężel-Czopek S 2012: Reproduction performance of cows with single, twin and triplet calves. Acta Vet Brno 4: 347-352

Schmutz SM, Moker JS, Clark EG, Orr JP 1996: Chromosomal aneuploidy associated with spontaneous abortion and neonatal losses in cattle. J Vet Diagn Invest 8: 91-95

Shiran S, Oryan A, Samadian MR 2010: Ectopia cordis in a male Holstein Friesian calf. Open Anat J 2: $34-36$

Slavik P, Jilek J, Brix M, Musilova L, Rajmon R, Klebanova P, Jilek F 2009: Health status of beef cows and their calves in the Czech Republic. Acta Vet Brno 1: 47-56

Wyrost P 1981: The results of studies on congenital cervical situs of the heart in domestic animals. Folia Morphol (Prague) 29: 220-223

Wyrost P, Grabiński J 1976: Pregnancy and parturition in cow with congenital cervical situs of the heart. Med Wet (In Polish) 32: 6-7 
Plate IV

Frackowiak H. et al.: Congenital sternal ... pp. 51-54

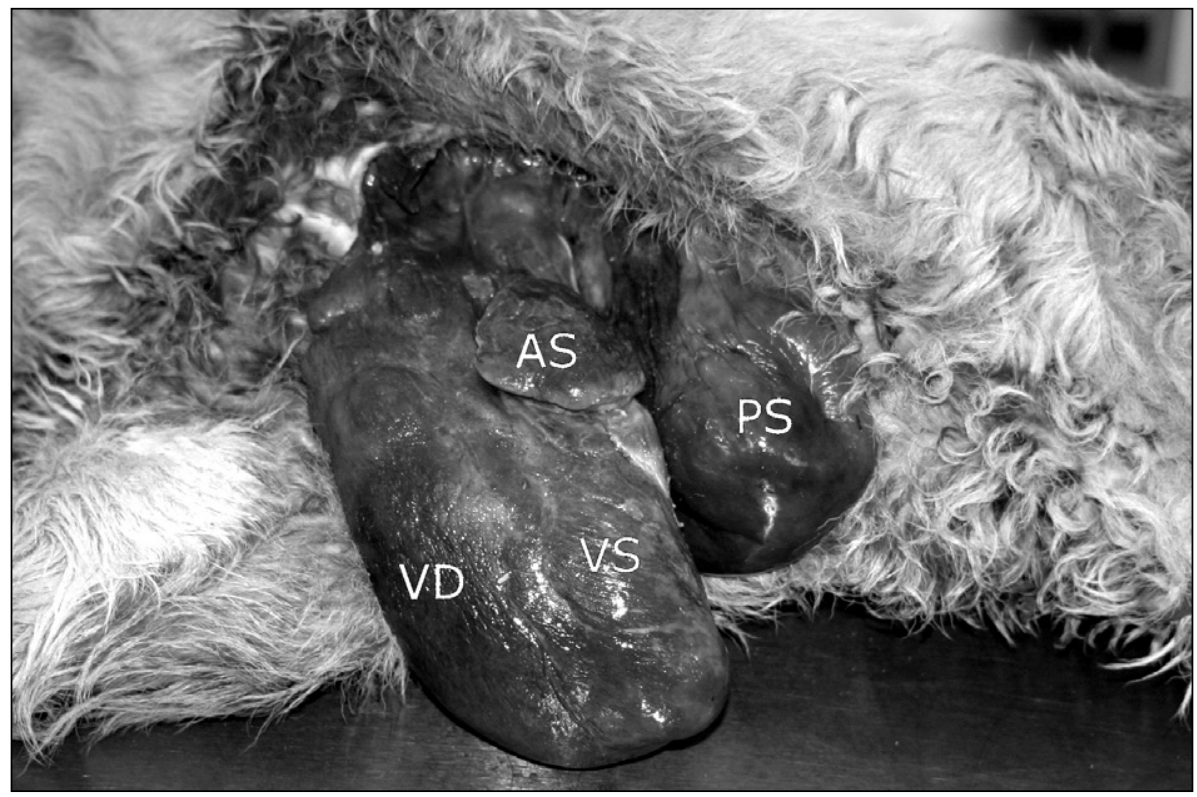

Fig. 1. Limousin calf with ectopia cordis (lateral view).

VD - ventriculus dexter, VS - ventriculus sinister, AS - auricula atrii sinistri, PS - pericardium serosum

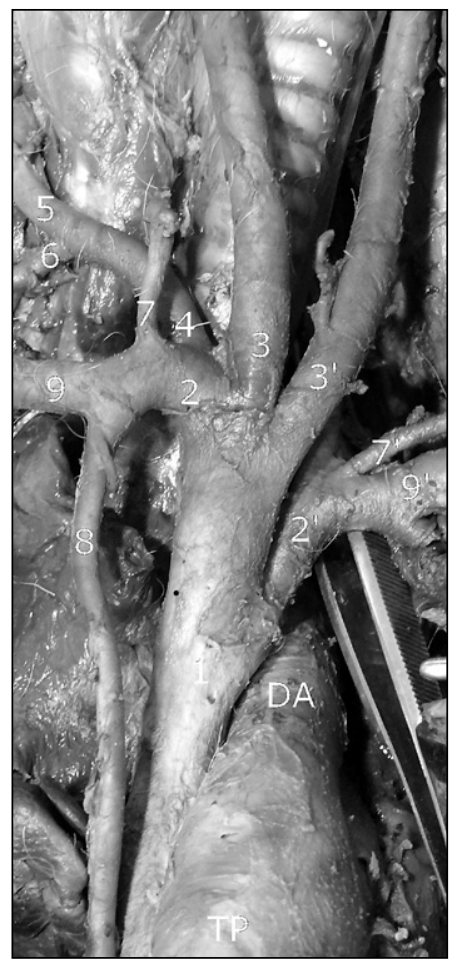

Fig. 2. Brachiocephalic trunk, pulmonary trunk and arterial duct in a Limousin calf with ectopia cordis (ventral view).

1 - truncus brachiocephalicus, 2 - arteria subclavia dextra, 2' arteria subclavia sinistra, 3 - arteria carotis communis dextra, 3 ' - arteria carotis communis sinistra, 4 - truncus costocervicalis dexter, 5 - arteria. cervicalis profunda dextra, 6 - arteria scapularis dorsalis dextra, 7 - arteria cervicalis superficialis dextra, 7' - arteria cervicalis 
Plate V

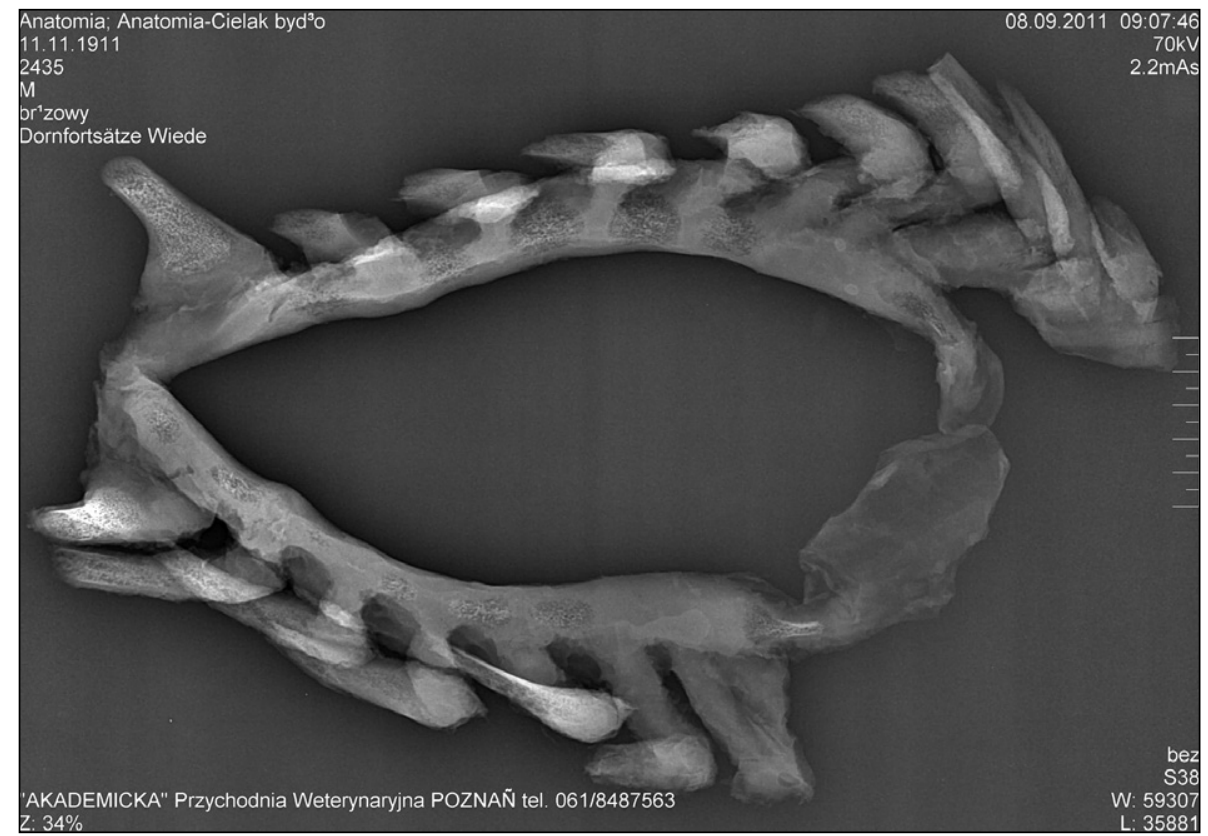

Fig. 3. Ring-like shape and 12 (or 6 pairs of ) cartilaginous bars of the Limousin calf sternum (x-ray). 